Check for updates

Cite this: RSC Adv., 2018, 8, 13401

\title{
Mesoporous NiO nanosphere: a sensitive strain sensor for determination of hydrogen peroxide $\dagger$
}

\author{
Qin Li, ${ }^{a}$ Wenbin Gao, ${ }^{a}$ Xiaopeng Zhang, ${ }^{a}$ Haitao Liu, ${ }^{\text {ab }}$ Meiling Dou, ${ }^{\text {ab }}$ \\ Zhengping Zhang*ab and Feng Wang (D) *ab
}

\begin{abstract}
Exploring the sensitive and reliable methods for the determination of hydrogen peroxide $\left(\mathrm{H}_{2} \mathrm{O}_{2}\right)$ is a crucial issue for the health and environmental challenges. Herein, we demonstrate a facile, but rational and effective solvothermal approach to the synthesis of hierarchical $\mathrm{NiO}$ mesoporous nanospheres ( $\mathrm{NiO}$ MNS) as an effective non-enzymatic sensor towards the $\mathrm{H}_{2} \mathrm{O}_{2}$ detection. Owing to the intercalation and stabilization effect of polyethylene glycol for the $\mathrm{Ni}(\mathrm{OH})_{2}$ intermediate, the $\mathrm{NiO}$ mesoporous nanosphere (NiO-MNS) product is consistent with the low-dimensional nanostructured NiO blocks with large surface area and plentiful mesopores after the calcination treatment. The obtained NiO-MNS sensor presents superior electrochemical performance with a high sensitivity $\left(236.7 \mu \mathrm{A} \mathrm{mM}^{-1} \mathrm{~cm}^{-2}\right)$ and low limit of detection $(0.62 \mu \mathrm{M})$, as well as the good selectivity and reliability for the further application of $\mathrm{H}_{2} \mathrm{O}_{2}$ detection. In addition, the unraveling mechanism of the mesopores formation derived from the in situ measurements also offers the valuable guidance for the future design of porous materials for electrochemical devices and other applications.
\end{abstract}

Received 10th February 2018
Accepted 27th March 2018

DOI: $10.1039 / \mathrm{c} 8 \mathrm{ra0} 1313 f$

rsc.li/rsc-advances noble metals have greatly limited the practical application and large-scale commercialization. Among the non-noble metal materials studied, transition metal oxides have attracted the most interest owing to their low-cost, stable physical/chemical property and environmental benignity. ${ }^{13-17}$

As one of the potential candidates for transition metal oxide sensors, $\mathrm{NiO}$ is one kind of the efficient $\mathrm{H}_{2} \mathrm{O}_{2}$ sensing materials for the electrocatalytic oxidation from its redox couple of $\mathrm{Ni}(\mathrm{II}) /$ $\mathrm{Ni}(\mathrm{III})$ in the alkaline electrolyte. To make the NiO sensor employed in practical application, great efforts have been devoted to the improvement of its electrochemical performance. ${ }^{18-20}$ Nevertheless, limited by the inherently poor electronic conductivity and large volume changes, the design of $\mathrm{NiO}$ as a high-efficiency sensor mainly focuses on optimizing the nanoarchitectures to enhance the electrochemical reactivity. Due to the crosslinking texture with large surface area and rational porous structure, hierarchical porous nanomaterials, which are assembled by low-dimensional nanostructured blocks, represent the enhanced electronic conductivity, increased active sites and facilitated mass-transfer ability. ${ }^{21-24}$ In order to obtain such unique electronic properties and structural features, various synthetic methodologies have been attempted. ${ }^{25-30}$ As one of the efficient methodologies, the solvothermal synthetic process can make nickel ions slowly hydrolyze with the $\mathrm{H}_{2} \mathrm{O}$ molecules from the nickel salt hydrate without alkaline precipitants, which can make more precise control over surface properties, phases, and architectures.

Herein, we report a facile, but rational and effective approach to the synthesis of 3D hierarchical NiO mesoporous 
nanospheres (NiO-MNS) by polyol-mediated solvothermal without alkaline precipitants. Ethylene glycol (EG) and a spot of polyethylene glycol (PEG) were employed as solvent and stabilizer, respectively. Owing to the contribution of PEG to the direction of $\mathrm{Ni}(\mathrm{OH})_{2}$ intermediates and the effect of pore formation during the calcination process, the obtained NiO nanospheres with low-dimensional nanostructured NiO units and plentiful porous structure should exhibit excellent electrochemical performance. In addition, the unraveling mechanism of the formation of mesopores is also explored by in situ measurements to give the guidance for the future design of other porous materials.

\section{Experimental section}

\subsection{Synthesis of materials}

All chemicals were of analytical grade and used without further purification. In a typical procedure, $1.2 \mathrm{~g}$ of nickel chloride hexahydrate $\left(\mathrm{NiCl}_{2} \cdot 6 \mathrm{H}_{2} \mathrm{O}\right)$ and $2.2 \mathrm{~g}$ of anhydrous sodium acetate $\left(\mathrm{CH}_{3} \mathrm{COONa}\right)$ were dissolved in $40 \mathrm{~mL}$ of ethylene glycol (EG) to form a homogeneous solution at room temperature. After that, $0.1 \mathrm{~g}$ of polyethylene glycol (PEG, molecular weight $=$ 1000) was introduced into the above solution under constant stirring for $30 \mathrm{~min}$. The mixture was then transferred into a Teflon-lined stainless steel autoclave, sealed, and maintained at $180{ }^{\circ} \mathrm{C}$ for $3 \mathrm{~h}$. After completely cooling down, the greenish product was collected by centrifuging, washing with deionized water and ethanol, and drying at $80^{\circ} \mathrm{C}$ for $12 \mathrm{~h}$. The obtained $\mathrm{Ni}(\mathrm{OH})_{2}$ intermediate is denoted as PEG/EG-Ni(OH $)_{2}$, which represents the $\mathrm{Ni}(\mathrm{OH})_{2}$ derived from PEG and EG. For comparison, the $\mathrm{Ni}(\mathrm{OH})_{2}$ intermediate was prepared in the same method without PEG involved (denoted as EG-Ni( $(\mathrm{OH})_{2}$ ). After calcined in an air atmosphere at $300{ }^{\circ} \mathrm{C}$ for $7 \mathrm{~h}$, the PEG/ EG-Ni(OH $)_{2}$ and EG-Ni(OH $)_{2}$ nanospheres were generated into $\mathrm{NiO}$ mesoporous nanosphere (NiO-MNS) and NiO nanosphere (NiO-NS), respectively. The structure and morphology are measured by the further characterizations.

\subsection{Structural and electrochemical characterization}

The scanning electron microscope (SEM, JEOL 6701F), transmission electron microscope (TEM, JEOL JEM-2000FE) were used to investigate the morphology and microstructure of the as-synthesized samples. The X-ray powder diffraction (XRD, Rigaku D/Max 2500 VB2+/PC, $\mathrm{Cu}$ K $\alpha$ radiation, $\lambda=1.54056 \AA$, 30 $\mathrm{kV}, 4^{\circ} \mathrm{min}^{-1}$ ) was carried out to evaluate the phase of the asprepared products. The Nanometrics HL5550 cryostat was performed to measure the electrical conductivity, based on the standard four-probe technique. The specific surface area and the pore structure were determined by nitrogen adsorptiondesorption isotherms on a Micromeritics Tristar 3020II instrument. The thermal gravimetric-infrared (TG-IR) spectra in this work were performed as in situ measurement by the thermal gravimetric-differential thermal analysis (TG-DTA, MettlerToledo) cooperated with a Nicolet 6700 Fourier infrared (Thermo Fisher) at a heating rate of $20{ }^{\circ} \mathrm{C} \mathrm{min}{ }^{-1}$ with heating region of $40-800{ }^{\circ} \mathrm{C}$ in an air atmosphere.
All electrochemical measurements were carried out on a CHI660E electrochemical station ( $\mathrm{CH}$ Instruments, Inc., Shanghai) equipped with a standard three-electrode cell maintained at $25^{\circ} \mathrm{C}$, using a saturated calomel electrode (SCE) as the reference electrode, a Pt wire as the counter electrode, and a modified glassy carbon electrode (GCE, geometric area of $0.071 \mathrm{~cm}^{-2}$ ) or a bare GCE as the working electrode. The modified working electrode was prepared as follows: $5 \mathrm{mg}$ of sample, $50 \mu \mathrm{L}$ of Nafion solution ( $5 \mathrm{wt} \%$, DuPont), and $1 \mathrm{~mL}$ of ethanol was mixed to form homogeneous ink by shaking and sonicating for $30 \mathrm{~min}$. Then, $6 \mu \mathrm{L}$ of the homogeneous ink was loaded onto the GCE and evaporated under an ambient atmosphere. Before modifying, the GCE was polished with aluminium paste $(0.05 \mu \mathrm{m})$, and then ultrasonically rinsed with deionized water and dried in air. All electrochemical testing is measured in $0.1 \mathrm{M} \mathrm{NaOH}$ solution. The reusability testing of NiO-MNS electrode was measured by the difference of two oxidation peaks current (at $0.45 \mathrm{~V}$ ) of the $\mathrm{CV}$ curves (with and without $1 \mathrm{mM} \mathrm{H}_{2} \mathrm{O}_{2}$ ) for every 7 days (stored at $4{ }^{\circ} \mathrm{C}$ ).

\section{Results and discussion}

\subsection{Morphology and structure}

The PEG/EG-Ni $(\mathrm{OH})_{2}$ and EG-Ni(OH $)_{2}$ intermediates were first observed with scanning electron microscopy (SEM, Fig. 1a and b). Compared with the EG-Ni(OH) $)_{2}$ intermediate (an average diameter of $650-950 \mathrm{~nm}$ ), which is derived from EG solution without the addition of PEG, the PEG/EG-Ni $(\mathrm{OH})_{2}$ intermediate exhibits the more uniform nanospheres (an average diameter of 700-800 nm) consistent with more clearly hierarchical silkflower texture. After the calcination treatment, the NiO-MNS sample, derived from the PEG/EG-Ni(OH $)_{2}$ intermediate, exhibits the broccoli-like architecture with the evenly rough surface (Fig. 1c), but the surface structure of NiO-NS has been broken and disorganized (Fig. 1d). Furthermore, we carried out transmission electron microscopy (TEM) to reveal the internal structure of these nanospheres. It is clear that the NiO-MNS is constructed by numerous nanoparticle units (the average size of ca. $10 \mathrm{~nm}$ with the close $d$-spacing of $0.24 \mathrm{~nm}$ ), which are interconnected with each other (Fig. 1e and g). Additionally, many mesopores are observed in the broccoli-like architectures of NiO-MNS; however, as for NiO-NS, the nanostructured units and obvious porous structure are not detected, which indicates that the bulk texture is generated from $\mathrm{Ni}(\mathrm{OH})_{2}$ intermediate derived from EG solvent without the addition of PEG (Fig. 1f). The electron microscopy images indicate that a spot of PEG, as the stabilizer and morphology-directing agent, may induce the growth of $\mathrm{Ni}(\mathrm{OH})_{2}$ in the sheet-like directions and improve the size uniformity, which favors the PEG/EG-Ni(OH $)_{2}$ intermediate generating into NiO-MNS with broccoli-like texture and mesoporous structure. Both NiO-MNS and NiO-NS exhibit the same diffraction rings, which indexes to the (111), (200), (220), (311) and (222) planes of NiO, in selected area electron diffraction (SAED) pattern (Fig. S1 $\dagger$ ). The result reconfirm the formation of NiO nanoparticles.

To further confirm the porous structure of NiO-MNS, nitrogen adsorption-desorption measurements were 

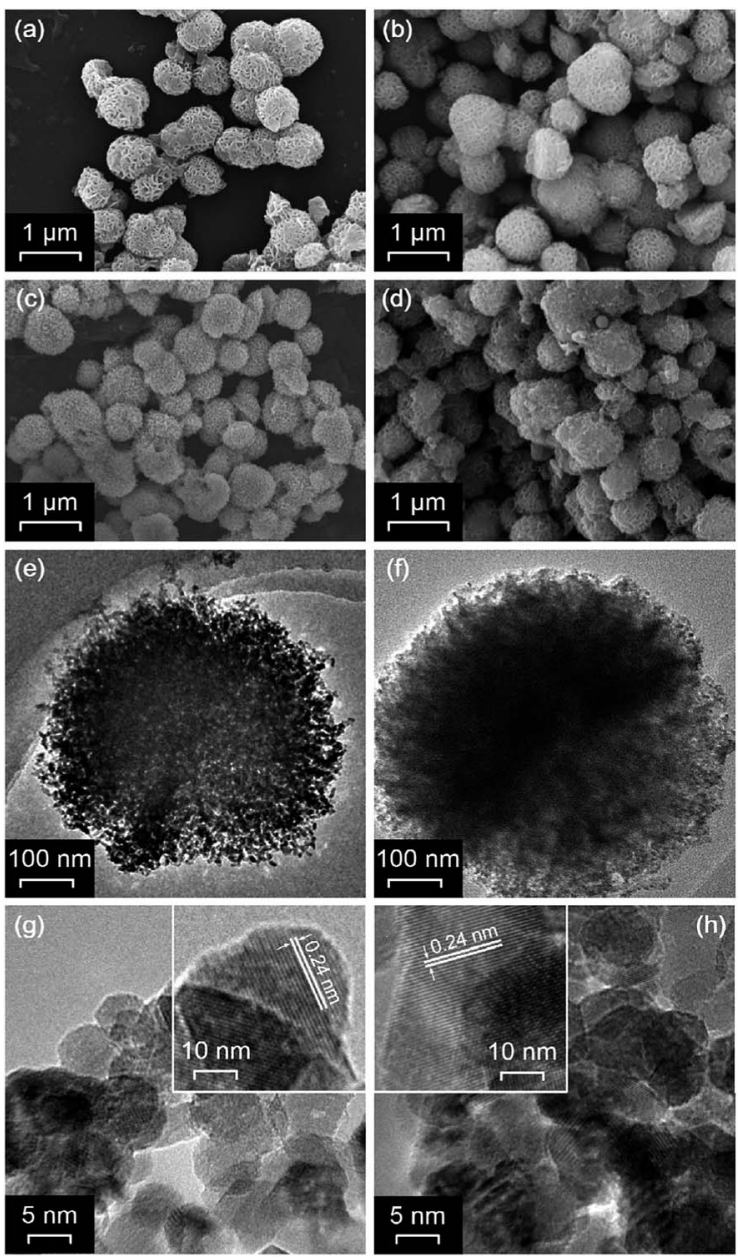

Fig. 1 SEM images of (a) PEG/EG-Ni(OH) ${ }_{2}$, (b) EG-Ni(OH) $)_{2}$, (c) NiOMNS and (d) NiO-NS. TEM and the corresponding high-resolution TEM images of the (e and g) NiO-MNS and ( $f$ and $h$ ) NiO-NS samples.

performed for all the final NiO products and $\mathrm{Ni}(\mathrm{OH})_{2}$ intermediates (Fig. 2a). Contrary to PEG/EG-Ni(OH $)_{2}\left(14.2 \mathrm{~m}^{2} \mathrm{~g}^{-1}\right)$ and EG-Ni(OH $)_{2}\left(18.7 \mathrm{~m}^{2} \mathrm{~g}^{-1}\right)$, both NiO-MNS and NiO-NS shows the significantly increased Brunauer-Emmett-Teller (BET) surface area of 113.6 and $85.2 \mathrm{~m}^{2} \mathrm{~g}^{-1}$, respectively. Especially, the NiOMNS sample exhibits apparently type-IV isotherm characteristics of mesopores with much larger surface area than NiO-NS. In addition, Barrett-Joyner-Halenda (BJH) pore size distributions (Fig. 2b) calculated by the nitrogen desorption branches reconfirm the presence of mesopores with diameters $<20 \mathrm{~nm}$ in the NiO-MNS samples, as well as a higher pore volume $\left(0.22 \mathrm{~cm}^{3}\right.$ $\left.\mathrm{g}^{-1}\right)$ than NiO-NS $\left(0.10 \mathrm{~cm}^{3} \mathrm{~g}^{-1}\right)$. We believe that such large surface area, high pore volume and mesoporous structure in the NiO-MNS product, but not in NiO-NS, may be mostly probably caused by the original structure of the $\mathrm{Ni}(\mathrm{OH})_{2}$ intermediates. Therefore, X-ray diffraction (XRD) patterns were obtained to explore the crystalline phases of the $\mathrm{NiO}$ products and $\mathrm{Ni}(\mathrm{OH})_{2}$ intermediates. As shown in Fig. 2c, either NiO-MNS or NiO-NS presents a high crystalline degree of NiO phase, where the $37.2^{\circ}, 43.3^{\circ}, 62.9^{\circ}, 75.4^{\circ}$ and $79.4^{\circ}$ can be indexed to (111), (200), (220), (311) and (222) crystal planes, respectively. No other
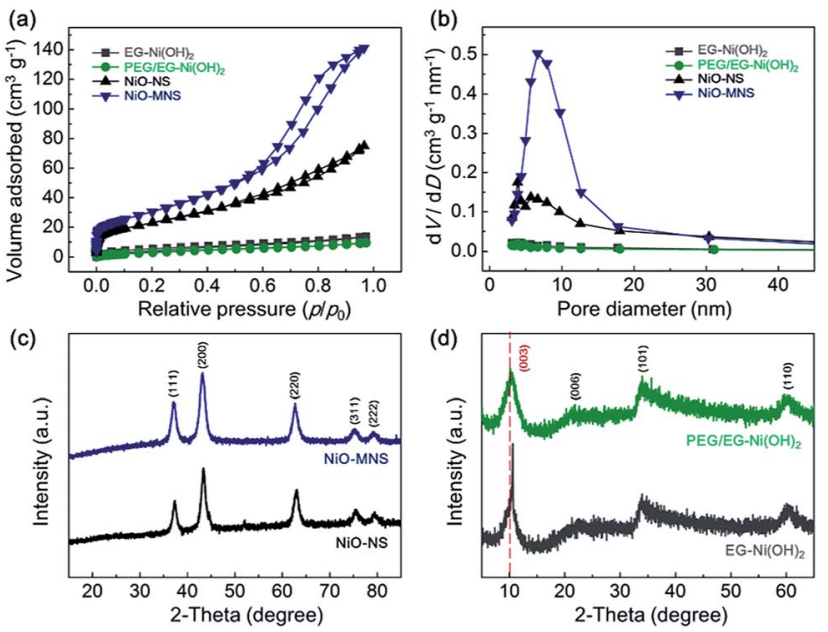

Fig. 2 (a) Nitrogen adsorption-desorption isotherms and (b) the corresponding $\mathrm{BJH}$ pore size distributions for the $\mathrm{NiO}$ products $(\mathrm{NiO}-$ MNS and $\mathrm{NiO}-\mathrm{NS}$ ) and the $\mathrm{Ni}(\mathrm{OH})_{2}$ intermediates (PEG/EG-Ni(OH) and $\left.\mathrm{EG}-\mathrm{Ni}(\mathrm{OH})_{2}\right)$. XRD patterns of (a) the $\mathrm{NiO}$ products and (b) the $\mathrm{Ni}(\mathrm{OH})_{2}$ intermediates.

peaks could be detected. These diffraction peaks are consistent with the face-centered cubic structure with the lattice parameter of $0.24 \mathrm{~nm}$, which correlates well with the lattice fringes of NiOMNS in the TEM profile. Furthermore, the XRD patterns of PEG/ EG-Ni( $(\mathrm{OH})_{2}$ and EG-Ni( $(\mathrm{OH})_{2}$ intermediates were investigated to the evolution of the NiO formation (Fig. 2d). The relative broad diffraction peak of PEG/EG-Ni(OH $)_{2}$ centered at $10.1^{\circ}$ refers to the (003) plane of $\alpha-\mathrm{Ni}(\mathrm{OH})_{2}$ with a low-angle-shift of the EG$\mathrm{Ni}(\mathrm{OH})_{2}\left(10.6^{\circ}\right)$ and complete crystal $\left(11.3^{\circ}\right.$, JCPDS: no. 380715), suggesting that some impurities intercalate into the interlayered space in the $\mathrm{Ni}(\mathrm{OH})_{2}$ lattice.

To investigate the surface chemical structure of NiO-MNS and NiO-NS, we employed the X-ray photoelectron spectroscopic (XPS) measurements and Raman spectra. The XPS survey spectra (Fig. S2 $\dagger$ ) of NiO-MNS and NiO-NS shows the presence of $\mathrm{Ni}$ (NiO-MNS: 43.1 at\%; NiO-NS: 43.6 at\%) and O (NiO-MNS: 56.9 at\%; NiO-NS: 56.4 at\%) with similar element contents (Table S1 $\dagger$ ). In addition, the high-resolution XPS of Ni 2p spectra were deconvoluted into $\mathrm{Ni}(\mathrm{II}), \mathrm{Ni}(\mathrm{III})$ and satellite peaks designated to their oxidized surface, ${ }^{31}$ and $\mathrm{O} 1$ s spectra were deconvoluted into metal-oxygen (O1), oxygen deficiency (O2) and metal-hydroxyl (O3) species (Fig. S3†). Compared with NiONS, the higher $\mathrm{O} 2$ content of NiO-MNS indicates a larger number of the low oxygen coordination defect sites, which promote the adsorption of $\mathrm{H}_{2} \mathrm{O}$ molecules and $\mathrm{OH}^{-}$ions and enhance the electrochemical activity of NiO-MNS. ${ }^{32}$ Furthermore, the Raman spectra (Fig. S4†) of the NiO-MNS and NiO-NS exhibits the peaks at about $490 \mathrm{~cm}^{-1}$ and $1130 \mathrm{~cm}^{-1}$, referring to the first-order longitudinal optical (1LO) and second-order longitudinal optical (2LO) phonon modes of $\mathrm{NiO}$, respectively. ${ }^{33}$

In order to elucidate the origin of enlarged surface area of the NiO-MNS products and the intercalation in the $\mathrm{Ni}(\mathrm{OH})_{2}$ intermediates, we performed PEG/EG-Ni( $(\mathrm{OH})_{2}$ and EG-Ni(OH $)_{2}$ by the thermal gravimetric-differential thermal analysis (TG- 
DTA) measurements and the thermal gravimetric-infrared (TGIR) spectra to comprehensively elucidate the mechanism of the formation process from the $\mathrm{Ni}(\mathrm{OH})_{2}$ intermediates to $\mathrm{NiO}$ products. In an air atmosphere, the PEG/EG-Ni(OH $)_{2}$ and EG$\mathrm{Ni}(\mathrm{OH})_{2}$ intermediates show the exothermic peaks located at 326 and $301{ }^{\circ} \mathrm{C}$, respectively (Fig. 3a). These obviously exothermic peaks were ascribed to the thermolysis during the formation of $\mathrm{NiO}$ from $\mathrm{Ni}(\mathrm{OH})_{2}$. Notably, the PEG/EG-Ni(OH $)_{2}$ presents not only a higher thermal stability but a larger weight loss (54.6 wt\%) compared with EG-Ni(OH $)_{2}(46.1 \mathrm{wt} \%)$. It is believed that the NiO-MNS intermediate should release more small molecules than NiO-NS, which can produce more pores. Meanwhile, compared with the theoretical weights loss (29.7 wt\%) derived from $\alpha$-Ni(OH $)_{2}$ (JCPDF: no. 38-0715) to NiO, both PEG/EG-Ni(OH $)_{2}$ and EG-Ni $(\mathrm{OH})_{2}$ exhibit large weight loss, demonstrating that the released small molecules are not just water steam from the hydroxide dehydration. Therefore, TG-IR spectra was employed to further analyze the gaseous decomposition during the calcination treatment (Fig. 3b). The IR spectra of gaseous decomposition are shown in the temperature region from 240 to $440{ }^{\circ} \mathrm{C}$. As for both PEG/EG-Ni(OH $)_{2}$ and EG$\mathrm{Ni}(\mathrm{OH})_{2}$, the gaseous decomposition shows the strongest signal intensity at the exothermic peak temperature. To better study the components of gaseous decomposition, we selected the IR spectra derived from the exothermic peak temperatures for PEG/EG-Ni( $(\mathrm{OH})_{2}\left(326^{\circ} \mathrm{C}\right)$ and EG-Ni(OH $)_{2}\left(301{ }^{\circ} \mathrm{C}\right)$. As shown in Fig. 3c, a series characteristic bands of $\mathrm{H}_{2} \mathrm{O}$ (at $3400-4000 \mathrm{~cm}^{-1}$ ) and $\mathrm{CO}_{2}$ (at 2250-2360 $\mathrm{cm}^{-1}$ ) are observed in both of the two samples. Combined with the result of XRD, it indicates that the EG or PEG/EG is intercalated into the interlayered space in the $\mathrm{Ni}(\mathrm{OH})_{2}$ lattice. It is worth noting that the strong and obviously characteristic bands of $\mathrm{CO}$ at $2030-2240 \mathrm{~cm}^{-1}$ are detected in PEG/EG-Ni $(\mathrm{OH})_{2}$, inferring that the generation of $\mathrm{CO}$ is produced from the residual PEG of PEG/EG-Ni(OH $)_{2}$. During the calcination process of PEG/EG-Ni(OH $)_{2}$, the decomposed $\mathrm{H}_{2} \mathrm{O}$, $\mathrm{CO}_{2}$ and $\mathrm{CO}$ steams can act as pore forming agent to produce high specific surface area and large pore size. According to the literatures and our results, the feasible formation mechanisms of NiO-NS and NiO-MNS has been proposed in Fig. 3d. The spot of PEG not merely promotes to stabilize the nanospherical architectures, but also produces the mesoporous structure with the low-dimensional NiO blocks, which can provide large accessible surface area to accelerate the diffusion of the reactants and improve the electrochemical activity.

\subsection{Electrochemical testing}

To evaluate the electrochemical activity of the resultant NiO-NS and NiO-MNS electrodes, cyclic voltammetric (CV) measurements were first performed to investigate the electrocatalytic oxidation of hydrogen peroxide $\left(\mathrm{H}_{2} \mathrm{O}_{2}\right)$ in $0.1 \mathrm{M} \mathrm{N}_{2}$-saturated $\mathrm{NaOH}$ solution with and without $1 \mathrm{mM} \mathrm{H}_{2} \mathrm{O}_{2}$. As shown in Fig. 4a, both NiO-NS and NiO-MNS shows well-defined redox peaks (the reversible electron transfer of $\mathrm{NiO} / \mathrm{NiOOH}(\mathrm{II} / \mathrm{III})$, eqn (1)), but not for the bare GC electrode. The strong current responses with a clear oxidation peak (A1, A2; the oxidation from $\mathrm{NiO}$ to $\mathrm{NiOOH}$ ) at about $0.45 \mathrm{~V}$, and the reduction peaks (B1, B2; the reduction from $\mathrm{NiOOH}$ to $\mathrm{NiO}$ ) at about $0.35 \mathrm{~V}$. Owing to the larger surface area and more active sites, the NiOMNS (A1, $0.47 \mathrm{~V}$ ) exhibits a higher oxidation peak potential than the NiO-NS sample (A2, $0.43 \mathrm{~V})$. More respected, the NiO-MNS electrode shows a much larger anodic and cathodic current response than NiO-NS, attributing to its own numerous active sites and large accessible reactive interface. When we added the $\mathrm{H}_{2} \mathrm{O}_{2}$ solution into the alkaline solution, the anodic current responses (from $\mathrm{Ni}(\mathrm{II}) \mathrm{O}$ to $\mathrm{Ni}(\mathrm{III}) \mathrm{OOH}$ ) increased and the (a)

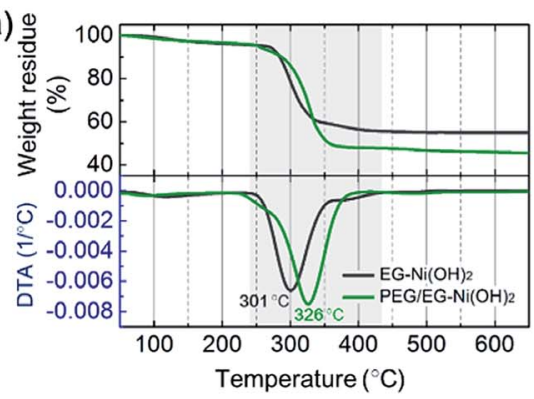

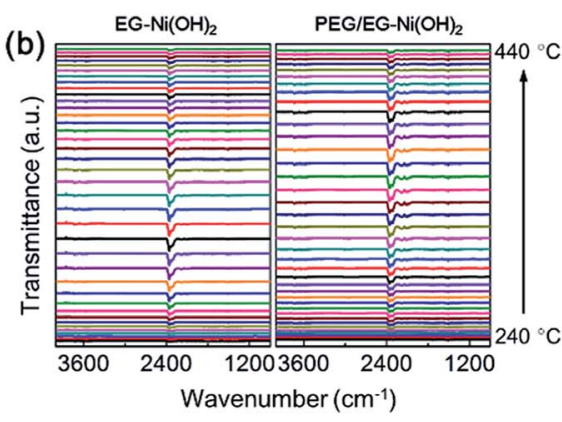

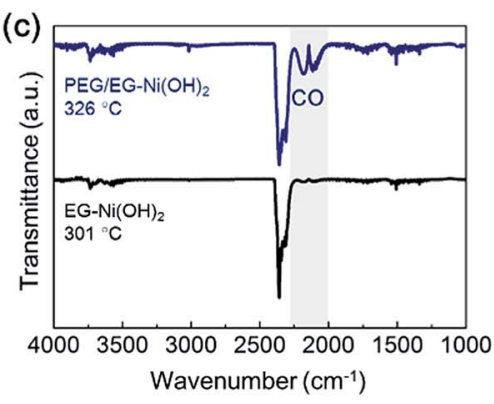

(d) $\mathrm{EG}-\mathrm{Ni}(\mathrm{OH})_{2} \rightarrow \mathrm{NiO}-\mathrm{NS}$

\begin{tabular}{|c|}
\hline $\begin{array}{l}E C \\
E C\end{array}$ \\
\hline PEG/EG-Ni(OH $)_{2} \quad \rightarrow \quad$ NiO-NS \\
\hline $\begin{array}{l}\mathrm{CH}_{3} \mathrm{COONa}+\mathrm{H}_{2} \mathrm{O} \leftrightarrow \mathrm{NaOH}+\mathrm{CH}_{3} \mathrm{COOH} \leftrightarrow \mathrm{Na}^{+}+\mathrm{OH}+\mathrm{CH}_{3} \mathrm{COO} \\
\mathrm{PEG}+\mathrm{EG}+\mathrm{Ni}^{2+} \leftrightarrow \mathrm{PEG} / \mathrm{EG}-\mathrm{Ni}^{2+}(\text { complex }) \\
\text { PEG/EG-Ni }{ }^{2+}(\text { complex })+\mathrm{OH}^{-} \leftrightarrow \mathrm{PEG} / \mathrm{EG}-\mathrm{Ni}(\mathrm{OH})_{2}(\mathrm{Complex}) \\
\text { PEG/EG-Ni(OH) })_{2}(\text { complex }) \rightarrow \mathrm{NiO}+\mathrm{H}_{2} \mathrm{O} \uparrow+\mathrm{CO}_{2} \uparrow+\mathrm{CO} \uparrow\end{array}$ \\
\hline
\end{tabular}
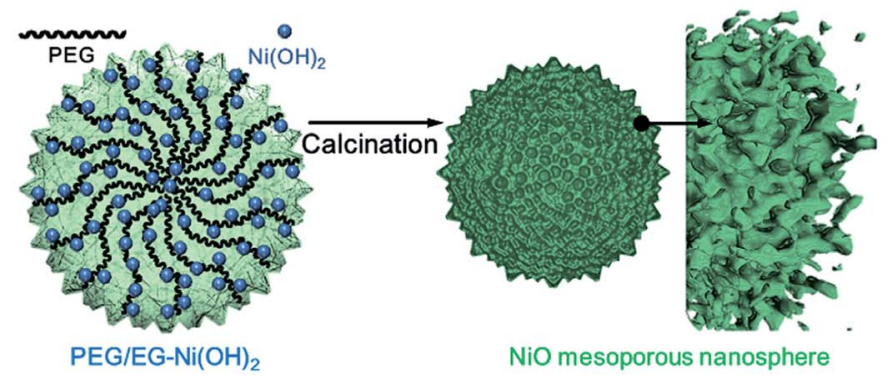

Fig. 3 (a) TG-DTA curves and (b) TG-IR patterns of PEG/EG-Ni(OH) $)_{2}$ and EG-Ni(OH) 2 in an air atmosphere. (c) FT-IR spectra of released decomposition of the heating PEG/EG-Ni(OH) (at $326{ }^{\circ} \mathrm{C}$ ) and $\mathrm{EG}-\mathrm{Ni}(\mathrm{OH})_{2}$ (at $301{ }^{\circ} \mathrm{C}$ ) derived from (b). (d) Illustration of the formation mechanism of NiO-MNS. 

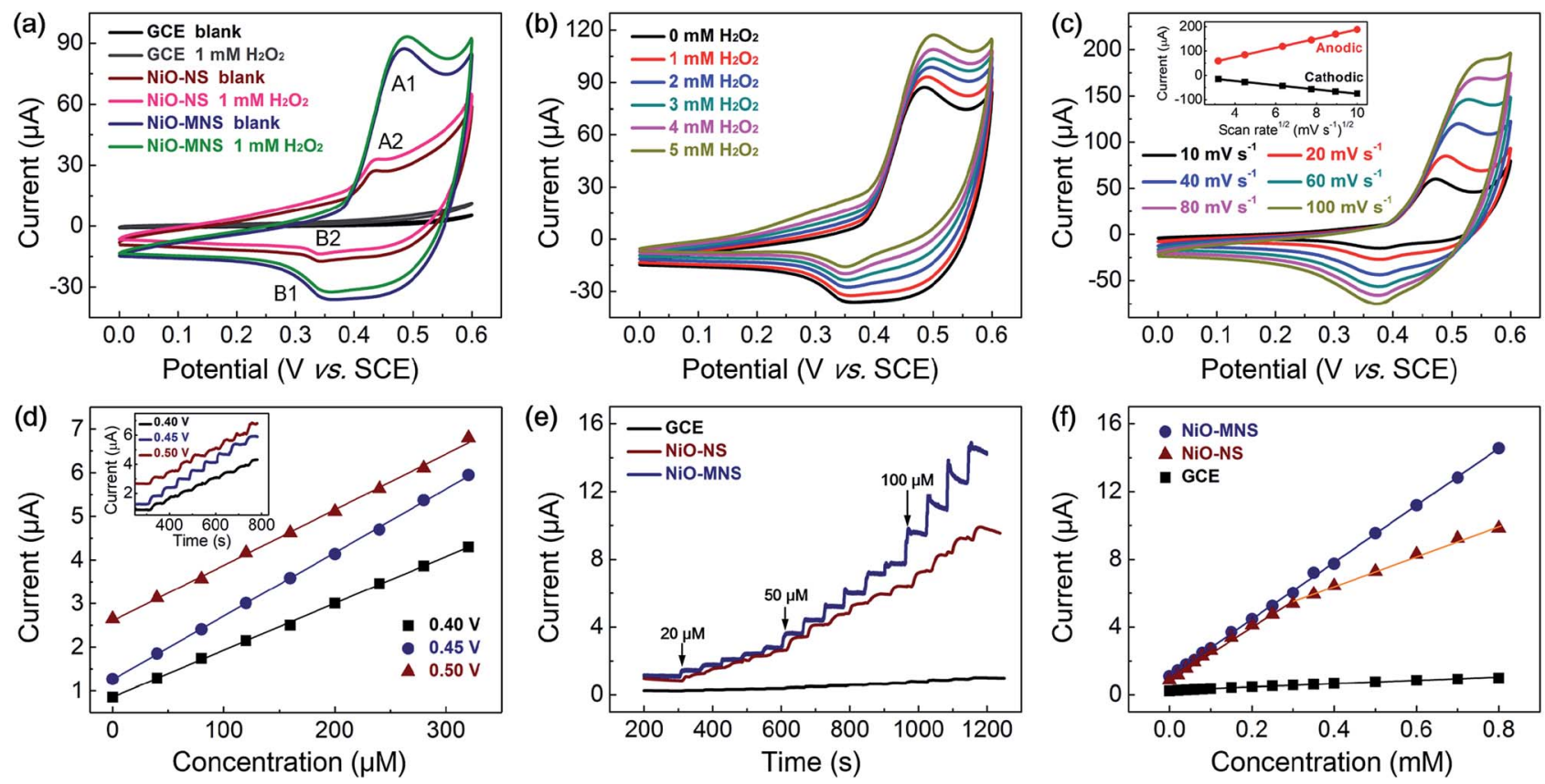

Fig. 4 (a) $\mathrm{CV}$ curves of the bare GCE, NiO-NS and $\mathrm{NiO}-\mathrm{MNS}$ electrodes with and without $1 \mathrm{mM} \mathrm{H}_{2} \mathrm{O}_{2}$. (b) $\mathrm{CV}$ curves of the NiO-MNS electrode with different $\mathrm{H}_{2} \mathrm{O}_{2}$ concentrations at a scan rate of $20 \mathrm{mV} \mathrm{s}^{-1}$. (c) $\mathrm{CV}$ curves the NiO-MNS electrode with different scan rates, and the inset in (c) shows the $\mathrm{Ni}(\mathrm{(I} / \mathrm{III})$ redox peak currents at different scan rates. (d) Linear relationship between the response current and the $\mathrm{H}_{2} \mathrm{O}_{2}$ concentration, and the inset in (d) shows chronoamperometric response of NiO-MNS towards the step injection of $40 \mu \mathrm{M} \mathrm{H}_{2} \mathrm{O}_{2}$ solution at different potentials. (e) Chronoamperometric response of GCE, NiO-NS and NiO-MNS towards the injection of hydrogen peroxide at $0.45 \mathrm{~V}$. (f) Linear relationship between the response current and the $\mathrm{H}_{2} \mathrm{O}_{2}$ concentration. Geometric loading of NiO-NS and NiO-MNS on the GCE is $425 \mu \mathrm{cm}{ }^{-2}$.

cathodic current responses (from $\mathrm{Ni}(\mathrm{III}) \mathrm{OOH}$ to $\mathrm{Ni}(\mathrm{II}) \mathrm{O}$ ) decreased, indicating that the $\mathrm{H}_{2} \mathrm{O}_{2}$ is mainly catalytic oxidized by $\mathrm{NiOOH}$, the oxidation of $\mathrm{NiO} / \mathrm{NiOOH}$ redox state. In the anodic sweep, the oxidation of $\mathrm{H}_{2} \mathrm{O}_{2}$ and the reduction of $\mathrm{NiOOH}$ take place simultaneously (eqn (2)). Moreover, the increased $\mathrm{NiO} / \mathrm{NiOOH}$ current responses (i.e., the decreased $\mathrm{NiOOH} / \mathrm{NiO}$ current responses) follow with more concentrated $\mathrm{H}_{2} \mathrm{O}_{2}$ (Fig. 4b). With the increased concentration of $\mathrm{H}_{2} \mathrm{O}_{2}$, more $\mathrm{NiO}$ is further oxidized to $\mathrm{NiOOH}$ causing an increased anodic current; meanwhile, more NiOOH is reduced by $\mathrm{H}_{2} \mathrm{O}_{2}$, which decreases the cathodic current response. The result reconfirms that the $\mathrm{H}_{2} \mathrm{O}_{2}$ oxidation current can be catalyzed by the electron transfer of $\mathrm{NiO} / \mathrm{NiOOH}(\mathrm{II} / \mathrm{III})$ redox state. The electrochemical processes can be formulated as follows:

$$
\begin{gathered}
\mathrm{Ni}(\mathrm{II}) \mathrm{O}+\mathrm{OH}^{-} \leftrightarrow \mathrm{Ni}(\mathrm{III}) \mathrm{OOH}+\mathrm{e}^{-} \\
2 \mathrm{Ni(III)}) \mathrm{OOH}+\mathrm{H}_{2} \mathrm{O}_{2} \rightarrow 2 \mathrm{Ni}(\mathrm{II}) \mathrm{O}+2 \mathrm{H}_{2} \mathrm{O}+\mathrm{O}_{2}
\end{gathered}
$$

Additionally, the anodic (or cathodic) current peaks only increase (or decrease) with minor voltage shift after $\mathrm{H}_{2} \mathrm{O}_{2}$ addition, demonstrating that the $\mathrm{H}_{2} \mathrm{O}_{2}$ oxidation reaction on the NiO-MNS surface is sustainable. The CV curves of NiO-MNS at various scan rates from 10 to $100 \mathrm{mV} \mathrm{s}^{-1}$ were also measured to further investigate the $\mathrm{H}_{2} \mathrm{O}_{2}$ sensing process (Fig. 4c). The current responses exhibit a pair of redox peaks at around 0.35$0.50 \mathrm{~V}$ with good symmetry, suggesting that the redox reaction of NiO-MNS is reversible. Moreover, the anodic and cathodic peak currents show linear relationship with the square root of the scan rate, revealing that the electron transfer of $\mathrm{NiO} /$ $\mathrm{NiOOH}(\mathrm{II} / \mathrm{III})$ process on the surface of the NiO-MNS is diffusion controlled. Combined with the diffusion of $\mathrm{H}_{2} \mathrm{O}_{2}$ on the electrode surface, the porous structure and surface area will impose the restrictions of the adsorption of $\mathrm{H}_{2} \mathrm{O}_{2}$ on the active sites of the sensor surface. Hence the sensitive surface reaction and mesoporous structure promise NiO-MNS further to have a good application in a $\mathrm{H}_{2} \mathrm{O}_{2}$ electrochemical sensor.

Because the working potential of the electrochemical sensor is also one of the main detection conditions, the optimal working potential of NiO-MNS is explored by the chronoamperometric response with the step-by-step injection of 40 $\mu \mathrm{M} \mathrm{H}_{2} \mathrm{O}_{2}$ at potentials of $0.40,0.45$ and $0.50 \mathrm{~V}$ (the inset in Fig. 4d). As shown in Fig. 4d, three good linear dependences of the typical chronoamperometric response of $\mathrm{H}_{2} \mathrm{O}_{2}$ oxidation current versus the $\mathrm{H}_{2} \mathrm{O}_{2}$ concentration were observed without obviously competitive reactions and noise background current. Compared with the working potential of 0.40 and $0.50 \mathrm{~V}$, the sensitivity at $0.45 \mathrm{~V}$ is so high that the potential of $0.45 \mathrm{~V}$ is selected as the optimum working potential for the further detection of $\mathrm{H}_{2} \mathrm{O}_{2}$. We also optimize the working potential of NiO-NS, the optimal potential for chronoamperometric test of NiO-NS is also about $0.45 \mathrm{~V}$ (Fig. S5†). In addition, this result is consistent with the oxidation peak potential of $\mathrm{NiO} / \mathrm{NiOOH}(\mathrm{II} / \mathrm{II})$ derived from the $\mathrm{CV}$ measurements.

To better elaborate the merits of mesoporous structure in the NiO-MNS sensor, we evaluated the chronoamperometric 
Table 1 Analytical performance characteristics for other electrochemical sensors reported for $\mathrm{H}_{2} \mathrm{O}_{2}$ detection ${ }^{a}$

\begin{tabular}{|c|c|c|c|c|}
\hline Electrode & Detection limit $(\mu \mathrm{M})$ & Linear range (mM) & $\begin{array}{l}\text { Sensitivity } \\
\left(\mu \mathrm{A} \mathrm{mM} \mathrm{m}^{-1} \mathrm{~cm}^{-2}\right)\end{array}$ & Reference \\
\hline $\mathrm{CuCo}_{2} \mathrm{~S}_{4}$ & 0.084 & - & 857.1 & 5 \\
\hline NiO nanosheets on GS & 0.4 & Up to 4 & 1077 & 18 \\
\hline NiO-SPE & 3.22 & $0.011-2.4$ & 807 & 3 \\
\hline $\mathrm{NiO}$ /graphene & 0.7664 & $0.25-4.75$ & 591 & 20 \\
\hline Grass-like $\mathrm{CuO}$ & 5.5 & Up to 0.9 & 137.17 & 35 \\
\hline ITO/NiO & 5.2 & $0.01-0.87$ & 41.36 & 36 \\
\hline $\mathrm{NiO} / \mathrm{ITO}$ & $1.28 \mathrm{mM}$ & $0.01-1$ & 1150 & 37 \\
\hline Ni(II)-MOF/CNTs & 2.1 & $0.01-51.6$ & 115.49 & 38 \\
\hline Cubic $\mathrm{Cu}_{2} \mathrm{O}$ & 1.61 & $0.5-8.5$ & 25 & 39 \\
\hline NiO-MNS & 0.62 & $0.01-0.8$ & 236.67 & This work \\
\hline
\end{tabular}

${ }^{a}$ CF: carbon foam; NW: nanowires; GS: graphite sheet; SPE: screen printed electrode.

responses by the injection of $20-800 \mu \mathrm{M} \mathrm{H}_{2} \mathrm{O}_{2}$ at potentials of $0.45 \mathrm{~V}$ also with the comparison of NiO-NS and bare GCE (Fig. 4e). All the electrode shows the current responses towards successive addition of $\mathrm{H}_{2} \mathrm{O}_{2}$. Upon the addition of $\mathrm{H}_{2} \mathrm{O}_{2}$, the steady-state current was obtained in less than $8 \mathrm{~s}$ for the NiOMNS electrode, which is much faster than NiO-NS (13 s) and GCE $(15.4 \mathrm{~s})$. The corresponding calibration curves for $\mathrm{H}_{2} \mathrm{O}_{2}$ detection on the above three electrodes are shown in Fig. 4f. The bare GCE exhibits a rather low sensitivity $\left(13.6 \mu \mathrm{AmM}^{-1} \mathrm{~cm}^{-2}\right)$ towards the $\mathrm{H}_{2} \mathrm{O}_{2}$ addition. Contrary to the linear dependences of NiO-MNS in the $\mathrm{H}_{2} \mathrm{O}_{2}$ concentration range of $20-800 \mu \mathrm{M}$, the NiO-NS presents two narrower linear concentration ranges $(20-$ $300 \mu \mathrm{M}$ and $400-800 \mu \mathrm{M})$. Notably, despite the similar sensitivity of NiO-MNS and NiO-NS (236.7 and $218.4 \mu \mathrm{AmM}^{-1} \mathrm{~cm}^{-2}$, respectively) at the low concentration range $(20-300 \mu \mathrm{M})$, the NiO-MNS electrode maintains such high sensitivity in much wide concentration range $(20-800 \mu \mathrm{M})$, but the NiO-NS only exhibits the much low sensitivity $\left(124.7 \mu \mathrm{A} \mathrm{mM}{ }^{-1} \mathrm{~cm}^{-2}\right)$ in the high concentration range $(400-800 \mu \mathrm{M})$. In addition, the limit of detection (LOD) is also calculated as $0.62 \mu \mathrm{M}$ for NiO-MNS and $0.80 \mu \mathrm{M}$ for NiO-NS (signal/noise $=3$ ). These results demonstrate that the sensitivity depends on the intrinsic activity and directional electron transport, which is related with the species and conductivity of sensors, in the low concentration range;
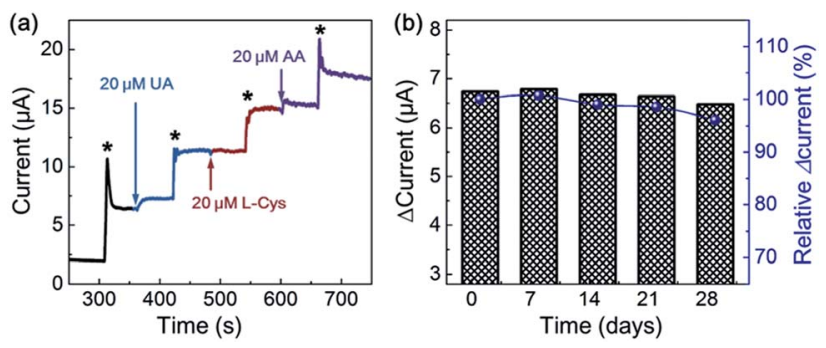

Fig. 5 (a) The chronoamperometric response to the addition of 200 $\mu \mathrm{M} \mathrm{H}_{2} \mathrm{O}_{2}$ solution (*) with interfering species (i.e., UA, L-Cys and $A A$ ) at $0.45 \mathrm{~V}$. (b) Reusability of the NiO-MNS sensor toward hydrogen peroxide analysis by $\mathrm{CV}$ measurements (with and without $1 \mathrm{mM} \mathrm{H}_{2} \mathrm{O}_{2}$ in $0.1 \mathrm{M} \mathrm{NaOH}$ solution) for four consecutive weeks. however, the facile diffusion of the electrolyte and reactant is a significant factor to accelerate the electrochemical response in the high concentration range. Hence, as for the NiO-MNS electrode, the nanoarchitectures constructed from the interconnected NiO blocks with the dominant mesoporous structure can offer numerous accessible active sites, facilitate both the electron and mass transport, and thereby enhance its electrochemical performance. We also summarized the sensing performances of typical non-enzymatic and non-precious metal electrochemical materials for $\mathrm{H}_{2} \mathrm{O}_{2}$ detection. The statistics reveals that the electrochemical sensing performance of the NiO-MNS electrode is comparable with the best reported transition metal oxides materials (Table 1 ).

To obtain the reproducibility of NiO-MNS, five parallel sensors derived from NiO-MNS were tested by chronoamperometric measurement (Fig. S6 and S7 $\dagger$ ). The relative standard deviation (RSD) is only $4.35 \%$. The selectivity of NiO-MNS to $\mathrm{H}_{2} \mathrm{O}_{2}$ was also investigated (Fig. 5a). The chronoamperometric responses of NiO-MNS to $\mathrm{H}_{2} \mathrm{O}_{2}$ is performed with the injection of some possible interfering species, including uric acid (UA), $\mathrm{L}(+)$-cysteine (L-Cys) and ascorbic acid (AA). With the NiO-MNS electrode at $0.45 \mathrm{~V}, 20 \mu \mathrm{M}$ additions of these interfering species do not exhibit apparent interferences to the detection of $200 \mu \mathrm{M} \mathrm{H}_{2} \mathrm{O}_{2}$, which indicates that the NiO-MNS sensor has a good selectivity for $\mathrm{H}_{2} \mathrm{O}_{2}$ detection and feasible application to determine $\mathrm{H}_{2} \mathrm{O}_{2}$ in real samples. In addition, the reproducibility of the NiO-MNS electrode was measured by the five successive $\mathrm{CV}$ results for four consecutive weeks (stored at $4{ }^{\circ} \mathrm{C}$, Fig. $5 \mathrm{~b}$ ). The attenuation of normalized current is only $4.0 \%$, indicating that the NiO-MNS sensor possesses remarkable reliability and stability for practical applications.

\section{Conclusions}

In summary, this work reports an effective solvothermal synthetic process with calcination at temperature of $300{ }^{\circ} \mathrm{C}$ to prepare NiO nanospheres which are constructed by the interconnected NiO blocks with the dominant mesoporous 
structure. Multiple characterizations are performed to confirm that the addition of PEG not merely promotes to construct the interconnected architectures, but also enhance the surface area with numerous mesopores. Thanks to the plentiful active sites and large accessible surface area, the NiO-MNS sensor presents

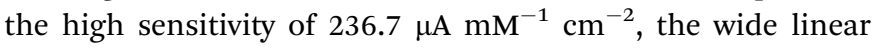
concentration range of $20-800 \mu \mathrm{M}$, the low limit of detection of $0.62 \mu \mathrm{M}$, as well as the good selectivity and reliability. Therefore, the NiO-MNS electrode is promising to be the potential sensor for the practical and feasible application towards the $\mathrm{H}_{2} \mathrm{O}_{2}$ detection. Moreover, the unraveling mechanism of the mesopores formation derived from the in situ measurements also gives the significant guidance for the future design of porous materials for other electrochemical devices.

\section{Conflicts of interest}

There are no conflicts to declare.

\section{Acknowledgements}

This work was supported by the National Natural Science Funds of China (51432003, 51125007).

\section{References}

1 W. Chen, S. Cai, Q. Q. Ren, W. Wen and Y. D. Zhao, Analyst, 2012, 137, 49.

2 M. Swieca, Food Chem., 2015, 180, 219.

3 P. Salazar, V. Rico and A. R. González-Elipe, Electrochim. Acta, 2017, 235, 534.

4 M. Li, H. Gao, X. Wang, Y. Wang, H. Qi and C. Zhang, Microchim. Acta, 2016, 184, 603.

5 Z. Yang, S. Zhang, Y. Fu, X. Zheng and J. Zheng, Electrochim. Acta, 2017, 255, 23.

6 M. Liu, S. He and W. Chen, Nanoscale, 2014, 6, 11769-11776.

7 A. A. Ensafi, H. A. Alinajafi, M. Jafari-Asl, B. Rezaei and F. Ghazaei, Mater. Sci. Eng., C, 2016, 60, 276.

8 T. Zhou, P. Lu, Z. Zhang, Q. Wang and A. Umar, Sens. Actuators, B, 2016, 235, 457.

9 M. Liu, R. Liu and W. Chen, Biosens. Bioelectron., 2013, 45, 206.

10 X. Wang, Q. Han, S. Cai, T. Wang, C. Qi, R. Yang and C. Wang, Analyst, 2017, 142, 2500.

11 D. Chen, X. Zhuang, J. Zhai, Y. Zheng, H. Lu and L. Chen, Sens. Actuators, B, 2018, 255, 1500.

12 J. Agrisuelas, M.-I. González-Sánchez and E. Valero, Sens. Actuators, B, 2017, 249, 499.

13 J. Zhang, W. Gao, M. Dou, F. Wang, J. Liu, Z. Li and J. Ji, Analyst, 2015, 140, 1686.
14 T. Zhou, W. Gao, Y. Gao, Q. Wang and A. Umar, RSC Adv., 2017, 7, 50087.

15 S. Muralikrishna, S. Cheunkar, B. Lertanantawong, T. Ramakrishnappa, D. H. Nagaraju, W. Surareungchai, R. G. Balakrishna and K. R. Reddy, J. Electroanal. Chem., 2016, 776, 59.

16 Z. Yang, Q. Sheng, S. Zhang, X. Zheng and J. Zheng, Microchim. Acta, 2017, 184, 2219.

17 S. Kogularasu, M. Govindasamy, S. M. Chen, M. Akilarasan and V. Mani, Sens. Actuators, B, 2017, 253, 773.

18 W. Liu, H. Zhang, B. Yang, Z. Li, L. Lei and X. Zhang, J. Electroanal. Chem., 2015, 749, 62.

19 S. Ci, T. Huang, Z. Wen, S. Cui, S. Mao, D. A. Steeber and J. Chen, Biosens. Bioelectron., 2014, 54, 251.

20 Z. Yu, H. Li, X. Zhang, N. Liu and X. Zhang, Talanta, 2015, 144, 1 .

21 Z.-X. Cai, H.-Y. Li, J.-C. Ding and X. Guo, Sens. Actuators, B, 2017, 246, 225.

22 J. Cao, S. Wang and H. Zhang, Mater. Lett., 2017, 202, 44.

23 Z. Yang, X. Zheng and J. Zheng, Sens. Actuators, B, 2017, 253, 34.

24 X. Zhang, G. Xu, Z. Chen, H. Cui, Z. Zhang and X. Zhan, Ceram. Int., 2017, 43, 4112.

25 M. Khairy and S. A. El-Safty, Sens. Actuators, B, 2014, 193, 644. 26 T. Zhu, J. S. Chen and X. W. Lou, J. Phys. Chem. C, 2012, 116, 6873.

27 A. K. Mondal, D. Su, Y. Wang, S. Chen, Q. Liu and G. Wang, J. Alloys Compd., 2014, 582, 522.

28 N. D. Hoa and S. A. El-Safty, Chem.-Eur. J., 2011, 17, 12896.

29 X. San, G. Zhao, G. Wang, Y. Shen, D. Meng, Y. Zhang and F. Meng, RSC Adv., 2017, 7, 3540.

30 C. Ray, S. Dutta, S. Sarkar, R. Sahoo, A. Roy and T. Pal, J. Mater. Chem. B, 2014, 2, 6097.

31 Z. Zhang, Y. Qin, M. Dou, J. Ji and F. Wang, Nano Energy, 2016, 30, 426.

32 L. Wang, X. Jiao, P. Liu, Y. Ouyang, X. Xia, W. Lei and Q. Hao, Appl. Surf. Sci., 2018, 427, 174.

33 M. Zhou, H. Chai, D. Jia and W. Zhou, New J. Chem., 2014, 38, 2320.

34 D. Wu, Z. Xu, T. Zhang, Y. Shao, P. Xi, H. Li and C. Xu, RSC Adv., 2016, 6, 103116.

35 P. Gao and D. Liu, Sens. Actuators, B, 2015, 208, 346.

36 S. Jana, G. Mondal, B. C. Mitra, P. Bera, B. Chakraborty, A. Mondal and A. Ghosh, New J. Chem., 2017, 41, 14985.

37 S. Jana, S. Samai, B. C. Mitra, P. Bera and A. Mondal, Dalton Trans., 2014, 43, 13096.

38 M.-Q. Wang, Y. Zhang, S.-J. Bao, Y.-N. Yu and C. Ye, Electrochim. Acta, 2016, 190, 365.

39 Y. Li, Y. Zhong, Y. Zhang, W. Weng and S. Li, Sens. Actuators, $B, 2015,206,735$. 